\title{
A mesma fé e o mesmo empenho em suas missões científicas e civilizadoras: os museus brasileiros e argentinos do século XIX
}

Maria Margaret Lopes Instituto de Geociências - UNICAMP

\section{RESUMO}

Este artigo traça paralelos entre os museus brasileiros e argentinos de História Natural na segunda metade do século XIX aborda os intercâmbios científicos estabelecidos. Os diretores de museus brasileiros e argentinos partilharam uma mesma fé inabalável nas ciências que entendiam como a garantia do progresso, e dedicaram-se ao que consideravam suas missões científicas e civilizadoras. Enfatizando ora seus vínculos com as ciências geológicas, ora com as ciências biológicas, ora com os estudos arqueológicos e antropológicos, alguns dos diretores dos museus latino-americanos do período foram indubitavelmente os responsáveis pela institucionalização de disciplinas na América Latina, tais como a Arqueologia, a Antropologia e a Paleontologia.

Palavras-chave: missões científicas; museus; História Natural.

\section{ABSTRACT}

This paper draws a parallel between Brazilian and Argentinian Museums of Natural History in the second half of the 19th century and deals with the scientific interchanges established between them. The directors of Brazilian and Argentinian Museums shared the same unshakable faith in science that they considered the warranty of progress and dedicate themselves to what they considered their scientific and civilizing missions. Emphasising in one moment geological sciences, in other archeological and anthropologial studies, some of the directors of Latin American Museums were undoubtly responsible for the institutionalization of disciplines in Latin American, such as Archeology, Anthropology and Paleontology.

Keywords: scientific missions; museums; Natural History. 
Os estudos recentes sobre História das Ciências no Brasil e na América Latina já reúnem uma ampla gama de excelentes monografias, ou estudos mais abrangentes, sobre os processos de aclimatação e consolidação das ciências naturais nestas regiões do mundo. Estes estudos, no entanto, contemplaram prioritariamente análises das relações, em geral assimétricas, que se estabeleceram entre os centros de investigação latinoamericanos e aqueles europeus ou norte-americanos. Pouca atenção têm merecido ainda, tanto os estudos comparativos, como os intercâmbios que instituições científicas e naturalistas mantiveram entre si no interior da própria América Latina, particularmente a partir da segunda metade do século XIX'1.

Nos últimos anos também os museus de história natural têm sido objeto de numerosas investigações baseadas em enfoques relacionados aos empreendimentos de ordenamento e domesticação da natureza dos séculos XVIII e XIX, que configuraram a História Natural enquanto disciplina moderna. Mesmo assim, até recentemente muito poucos historiadores se ocuparam em recuperar os fragmentos das memórias e amnésias dessas instituições, que também na América Latina exerceram papéis centrais na construção das ciências naturais. Traçar paralelos entre alguns dos museus argentinos e brasileiros ${ }^{2}$, da segunda metade do século XIX, como este artigo se propõe, é uma possibilidade aberta pela adoção de perspectivas latino-americanas que advertem que nossas histórias nacionais se diferenciaram menos do que agradava supor alguns anos atrás ${ }^{3}$. Nesse caso, abordagens comparativas são bastante úteis uma vez que, rompendo a rigidez de visões historiográficas que aprisionam a história dentro de fronteiras políticas, permitem tornar mais visíveis aquelas que são as marcas locais das sociedades estudadas e aqueles que são seus aspectos generalizadores.

Longe de qualquer intenção de contar exaustivas histórias institucionais sobre os museus argentinos e brasileiros da transição do século passado, compartilhamos o princípio de que independentemente de reservas, críticas, cetismo ou entusiasmo em relação ao poder das instituições, é inevitável, também no caso dos países latino-americanos, considerar as relações intrínsecas entre os processos de consolidação das atividades científicas e de sua institucionalização, os quais abrem caminhos ainda não trilhados aos estudos comparativos.

Nos marcos dos processos de consolidação das ciências como ocupação profissional, muitos dos construtores das ciências não só na América Latina, e particularmente no caso dos museus, estabeleceram e man- 
tiveram-se à frente de instituições, em cujas histórias dificilmente se pode diferenciar nitidamente linhas demarcatórias entre suas vidas, obras científicas e institucionais. Entre esses se situam Germán Conrad Burmeister (1807-1892) - naturalista prussiano -que dirigiu o Museu Público, depois Nacional de Buenos Aires por 30 anos, entre 1862 e 1892; e seu contemporâneo e colega Ladislau Netto (1838-1894) - naturalista brasileiro - que esteve à frente do Museu Nacional do Rio de Janeiro por mais de 25 anos, entre 1866 e 1893. Quando estes homens chegaram aos seus museus, embora enfatizassem em seus relatórios oficiais a pobreza das instituições que lhes cabia construir do nada, na verdade estavam chegando a instituições com mais de meio século de atividade ${ }^{5}$, que haviam passado por processos de renovação reunindo coleções nada desprezíveis que, pelo contrário, lhes interessaram profundamente.

\section{UM MUSEU EM TRÊS VOLUMES}

Desde a carta de apresentação e recomendação de Burmeister em sua primeira viagem ao sul da América, ao então presidente da Confederação Argentina, está presente a retórica comparativa entre os países latino-americanos, que acompanhará também as relações entre seus museus ao longo do século XIX:

Se atribuye á un Gobierno de S. América una medida de prohibición que privó á esos países da la felicidad de ser estudiados por el Baron de Humboldt á principios de este Siglo. Todos sabemos que el Dictador del Paraguay confiscó los manuscriptos sabios del señor Bonpland y defraudó á la Ciencia y á la América... A V. Excia., mi querido Señor Presidente, es dado hoi día reparar esas afrentas del América del Sud prodigando el apoyo y la consideración de nuestro ilustrado Gobierno á los sabios de la Europa que van, para darnos á conocer á nosotros mismos las riquezas de que somos por ahora poseedores inapercibidos ${ }^{6}$.

O apelo à ilustração do governo da Confederação era o argumento de força que tornava irrecusável o pedido de apoio à Burmeister. Ele ofereceu-se para dirigir o Museo Público de Buenos Aires depois de sua viagem pelo sul da América, em que conheceu e analisou as coleções dos museus do Rio de Janeiro, de Montevidéu, Buenos Aires, Paraná, e Lima. Paraná, então capital da Confederação Argentina, já contava entre suas diversas instituições com seu Museo Nacional organizado ${ }^{7}$. E, terminada a época de Rosas, a criação da Asociación de Amigos de la Historia Natural del Plata em 1854, para revigorar o Museo Público de Buenos Ai- 
res, pode ser entendida também como uma entre as várias medidas que visavam a uma contraposição às iniciativas políticas e culturais da Confederação Argentina. À iniciativa dessa Associação deveu-se `a duplicação das coleções do museu nos dois anos que antecederam a chegada de Burmeister a Buenos Aires.

Tanto no Paraná, como em Buenos Aires ou Rio de Janeiro, os interesses explícitos pela investigação dos recursos minerais - que nem sempre se evidenciaram tão promissores quanto se desejava -, conformaram ao lado das coleções botânicas, zoológicas, paleontológicas, arqueológicas e antropológicas as bases desses primeiros museus. Era no Museu Nacional de Paraná que se realizavam as análises dos produtos mineralógicos, como cobre, carvão, em que se esperava apoiar a viabilidade econômica da Confederação. O Museu Nacional do Rio de Janeiro funcionou desde sua fundação em 1818, até praticamente o final do século XIX, como um órgão consultor governamental para os assuntos de geologia, mineração e recursos naturais do Império, decorrendo daí a importância do seu laboratório de análises químicas. Por isso também vão sempre merecer destaques as coleções mineralógicas, quer coletadas pelas províncias no caso de Paraná e Rio de Janeiro, ou adquiridas para os estudos comparativos em Paris, no caso de Buenos Aires ou Freiberg, no caso brasileiro.

Aquele primeiro museu de Paraná teve vida curta. O Museo de Buenos Aires, a essa época bem menos estruturado que o do Rio de Janeiro, senão quantitativamente, qualitativamente já dispunha de coleções de valor para os estudos paleontológicos, que o Museu Nacional brasileiro jamais alcançou. E a qualidade e a novidade para a ciência, mais do que a quantidade das coleções era o que de fato importava nesses museus. E nisso, desde quando Burmeister chegou a Buenos Aires para dirigir o $\mathrm{Mu}-$ seo Público, este já não tinha rivais no que se referia às mesmo que modestas coleções fossilíferas. Burmeister se interessaria particularmente pelas coleções de mamíferos ante diluvianos que aí encontrou, algumas das quais haviam pertencido a destacados naturalistas da região. Mas Burmeister se dedicaria mesmo às coleções de Augusto Bravard. O engenheiro de minas francês, inspetor de minas da Confederação Argentina, colaborou com a Asociación de Amigos de la Historia Natural del Plata e com o museu de Buenos Aires e foi convidado a dirigi-lo, mas preferiu o cargo de diretor do museu de Paraná, que exerceu de 1858 a 1861, quando faleceu. Especialmente às coleções de Bravard já existentes no museu de Buenos Aires, e àquelas que seriam compradas após sua morte ${ }^{8}$, das quais Burmeister passou a ter também à sua disposição 500 gravuras pa- 
ra estudos, ele dedicou parte considerável de seus trabalhos nos Anales del Museo Público de Buenos Aires, de 1864 a 1891.

Entre a realização das viagens de exploração, a classificação das coleções e a publicação dos catálogos, que constituíram a essência da prática da história natural nos museus, seguramente Burmeister privilegiou a classificação das coleções e a publicação dos catálogos. Ele implantou em Buenos Aires um museu de caráter científico, local, especializado em Zoologia paleontológica. Dedicou-se desde suas primeiras publicações nos Anales à organização do catálogo do Museo; a “trazer para a ciência”, classificando, como já o fizera no Museu de Lima, por exemplo, em novos gêneros e espécies as peças das coleções que aí encontrou. Particularmente, aquelas que marcavam a singularidade do que os museus ajudariam a definir como o território argentino: a paleontologia dos grandes mamíferos extintos.

Burmeister suspendeu a publicação dos Anales em 1874, apelando à sua idade, ao direito de descansar sobre suas obras, farto de ser ao mesmo tempo restaurador de objetos fósseis, desenhista, escritor, etc. Os Anales só voltaram a ser publicados em 1883, sendo que durante esse período o museu não contou com nenhuma publicação oficial para manter o intercâmbio com outros museus estrangeiros. Mas se o museu ficou sem suas publicações oficiais, Burmeister, apesar de seus argumentos para suspender os Anales, no entanto não parou de publicar, tanto na Argentina como na Europa, suas próprias obras baseadas nas coleções do museu.

Contra essa situação se indignava em 1878 Eduardo Holmberg (18521937), um dos principais e influentes naturalistas de Buenos Aires, que seria o fundador e diretor do Jardim Zoológico de Buenos Aires, a partir de 1888. Chamava a atenção sobre o estado em que se achava o museu de Buenos Aires, dada a geral indiferença existente sobre aquela instituição indispensável para um país que pretendia elevar-se na escala do progresso. Considerava que Burmeister havia de fato tornado o estabelecimento o primeiro museu da América do Sul, mas isso não era mais suficiente. Reinava grande desordem na disposição das coleções, o posto de inspetor havia sido suprimido e, irônico, afirmava que "o diretor tem muito que fazer, as publicações européias exibem a cada ano suas numerosas observações (...), os Anales del Museo já não se publicam, e é necessário conhecer as obras européias para saber o que existe no museu de Buenos Aires $(. . .)^{9}$.

Os Anales foram retomados em 1883, e este tomo, o terceiro, foi concluído em 1891. Neste tomo se inclui um artigo de Carlos, filho de Bur- 
meister, naturalista-viajante do museu, sobre sua viagem à Patagonia austral Esses três tomos dos Anales são integralmente obra pessoal de Burmeister, à exceção do artigo de seu filho. As relações de importância entre as coleções existentes no museu e a publicação dos Anales, a princípio financiadas pela "Sociedad Paleontológica", são eloqüentemente explicitadas por Juán María Gutiérrez, presidente da sociedade e reitor da Universidad de Buenos Aires, a que então se vinculava o Museo Público:

Esas osamentas gigantescas que bajo cajas de cristal ostenta nuestro Museo Público, como verdaderas joyas, serían estériles para la ciencia y para los estudios de la Europa, si los Anales que vuestra generosidad costea, no transportaran en sus páginas al otro lado del Océano, la imagen, la descripción y las observaciones necesarias para que las comprendan y estudien los zoólogos extranjeros y distantes ${ }^{10}$.

Os catálogos vêm sendo os objetos mais importantes produzidos a partir das coleções desde o século XVI. Nos catálogos, as coleções através de suas imagens e descrições viajavam por territórios bem mais amplos que os salões apertados dos museus. Assim impressas, as coleções alcançavam públicos muito mais amplos do que aqueles que visitavam o mu60 seu, e ampliavam a possibilidade de coletar, organizar e comparar.

A publicação de tais Anales com suas pranchas de desenhos eram essenciais para os estudos de Zoologia, Botânica ou Paleontologia, que se baseavam em métodos comparativos. Cada ossada, cada planta, cada inseto encontrado era sistematicamente comparado aos outros já existentes nas coleções. Como dizia William Flower, diretor do Departamento de História Natural do Museu Britânico:

(...) se forman una idea de la multiplicidad de los ejemplares necesarios para resolver, aún los más simples problemas de la historia de la vida de los animales ó de las plantas. El naturalista debe con frecuencia rejistrar todos los museos, públicos e privados de Europa y de América para llegar á componer la monografia de un solo género comun ó aún de una espécie (...) Se vé obligado muchas veces á confessar que sus investigaciones han fracassado por falta de los materiales necesarios á su empresa ${ }^{11}$.

E, à falta de materiais, de coleções, haviam que fazer frente os catálogos, os livros. Ao evitar a qualquer custo o fracasso de seus estudos, Burmeister investiu quantidades razoáveis de dinheiro público na compra de livros, além de sua própria biblioteca particular que vendera ao museu, quando assumiu sua direção, e das obras que obtinha pelo intercâmbio 
dos Anales. Dedicou-se cuidadosamente a prover o Museo Público de Buenos Aires daquela que seria considerada uma das melhores bibliotecas de museus da América Latina de sua época. Desde a primeira entrega, os Anales foram enviados para as principais instituições científicas internacionais e, na América Latina, para a Biblioteca Imperial e Nacional Brasileira do Rio de Janeiro e para a Universidade Nacional de Chile.

Publicar e manter-se a par do que era publicado era (e talvez ainda seja até hoje) uma das maiores dificuldades dos naturalistas quer na Argentina ou no Brasil. Para isso a publicação dos Anales foi um instrumento utilíssimo. Para o final do século, a maioria dos museus latino-americanos em atividade publicou regularmente seus Anales, mesmo que por vezes, para desgosto de seus diretores, estes sofressem atrasos por conta de falta de verbas, dificuldades de impressão de desenhos, fotografias, quando não mudanças políticas na instituição ou no país. Entre essas publicações, chegaram aos museos argentinos e brasileiros e circularam regular e efetivamente, na América Latina da transição do século, os Anales do Museu do México, da Costa Rica, de El Salvador, British Guiana, Jamaica, Cuba, Venezuela, da Colombia, Bogotá; Paraense (Belém), Nacional do Rio de Janeiro, Museu Paulista, Nacional de Montevideu, de Buenos Aires, La Plata, Santiago, Valparaiso.

NOBRES RIVAIS, HONROSOS IMITADORES

Os intercâmbios entre o Museu de Buenos Aires e o Museu Nacional do Rio de Janeiro, que possivelmente se iniciaram pelo envio dos Anales del Museo Público, se intensificaram pelo menos a partir de 1869, quando produtos zoológicos e botânicos começaram a ser trocados para completar coleções ${ }^{12}$.

O Museu Nacional do Rio de Janeiro, que mantinha suas atividades desde 1818, havia passado, como o Museu de Buenos Aires, por um período de dinamização de suas atividades na década de 1850 . Seus diretores, à época, também organizados em torno da uma sociedade científica - a Sociedade Velloziana - tornariam público seus estudos sobre as coleções ali existentes no Museu, bem como a história do próprio museu nas sessões, atas e publicações associadas à sociedade. Reestruturado a partir de 1876, o Museu Nacional viveu seus dias de maior incremento de atividades científicas sob a direção de Ladislau Netto, que abandonou seus estudos botânicos para se dedicar exclusivamente ao museu, e particularmente às suas coleções arqueológicas e etnográficas. Contemporâneo de Burmeister, Ladislau Netto foi membro correspondente da Sociedad Cien- 
tífica Argentina desde setembro de 1876. Nomear sócios honorários e correspondentes foi um mecanismo bastante usual entre as associações científicas, o que, além de conferir mérito e reconhecimento a esses sócios e à sociedade que exibia seus nomes em suas publicações, garantia na maioria dos casos o incremento de publicações às associações, por troca, sem necessidade de compra das obras muitas vezes de alto custo.

Netto partilhava com Burmeister a importância essencial das publicações científicas, que cada vez mais, em função das facilidades e maior rapidez de transporte e comunicações, haviam se tornado o instrumento privilegiado do diálogo do mundo científico. Organizou os Archivos do Museu Nacional do Rio de Janeiro, que se constituiram na primeira revista brasileira regular e duradora exclusivamente dedicada às ciências naturais. Diferentemente de Burmeister, Ladislau Netto não faria dos Archivos do Museu Nacional do Rio de Janeiro um veículo de publicação de seus trabalhos científicos, os quais nunca atingiram as dimensões da obra de Burmeister. Sua obra e seu perfil empreendedor o aproximam bem mais em alguns aspectos de Francisco Pascásio Moreno, o construtor do museu de La Plata, no final do século. Divulgaria, sim, os trabalhos de seus colaboradores, que incluíam diversos naturalistas estrangeiros, à época diretores de seções do Museu Nacional, em uma estratégia de ampliar a divulgação de seu museu no exterior.

Os progressos do museu brasileiro, mencionados já desde o Tomo I dos Anales da Sociedad Cientifica Argentina de 1876, foram descritos novamente por Estanislao Zeballos em 1877:

Buenos Aires y Rio de Janeiro, son de las capitales sud-americanas, las que mas llaman la atención por sus establecimientos consagrados á las colecciones y estudios científicos. Así, el Museo Público de Buenos Aires, el templo mas famoso de los erigidos á la Paleontologia, ciencia de este siglo, y el de Rio de Janeiro comienza á atraerse las miradas del mundo científico, por sus tesoros de Historia Natural.

Zeballos termina seu artigo, no que poderia ser entendido como uma crítica à atuação isolada de Burmeister no Museo Público de Buenos Aires, "felicitando à los jóvenes sábios brasileros por sus progresos, y al Dr. Netto por el éxito que recompensa sus desvelos, hacemos votos porque la escuela científica brasileira, encuentre nobles rivales en la República Argentina" ${ }^{\prime \prime}$.

O uso retórico de se estabelecer comparações entre os principais museus do sul da América, que disputavam o primeiro lugar entre seus "no- 
bres rivais”, se mantinha, e de modo geral o seu sentido era o da crítica ou o do estímulo às instituições locais, por oposição à que se comparava. Em 1882, Ladislau Netto foi a Buenos Aires. Em 12 de outubro, foi realizada una Conferência Pública en sua honra na Sociedad Científica Argentina, então presidida por Carlos Berg, que à época dirigia também o pequeno museu da Sociedad. Ladislau Netto foi apresentado como "un distinguido huésped y uno de sus miembros corresponsales que ha venido á visitar las playas del Plata”; como "el conocido naturalista brasilero, Director General del Museo Nacional de Rio de Janeiro”.

Nessa reunião Ladislau Netto, que não fora um adepto de primeira ordem do darwinismo, fez algumas Observaciones sobre la teoria de la evolución. Dizendo ter sido convidado inesperadamente e explicando que se dedicava mais especificamente a investigações arqueológicas, “al exámen minucioso de algunas antigüedades prehistóricas americanas, que teve la felicidad de encontrar en esta ciudad", desculpava-se por apresentar apenas "algunas ideas sueltas como homenaje de consideracion a los colegas, y de cortesia á asistencia" sobre "tan elevada materia" - "el transformismo" 14 .

Nesta mesma "fiesta de familia", como Berg chamou a reunião, além de outros conferencistas, Francisco Moreno falou sobre El origen del Hombre Sud-Americano, destacando que os estudos da Antropologia Americana tomavam "nuevo impulso in situ", aos quais eram concedidos referendos científicos internacionais. Paul Broca, na Revue d'Anthropologie em 1874 e 1875, tornara conhecida na Europa a fundação do museo particular de Moreno e, no ano seguinte "anunciaba que [Moreno] habia tenido imitadores en el Brasil. El Museo de Rio de Janeiro abría una galeria antropológica y desde entónces el Director del establecimiento, el dr. Netto, el sábio infatigable que teneis delante, ha continuado dedicándose á esa gran ciencia"15.

Seguramente a Netto não deve ter agradado o adjetivo de imitador. Em 1882, antes de ir à Argentina, Netto havia organizado e inaugurado, em 29 de julho, a grande Exposição Antropológica Brasileira, que afirmava ter sido a primeira no gênero na América. Marco de uma época da história das ciências naturais e da Antropologia no Brasil, nessa exposição, mais do que coleções arqueológicas, etnográficas e antropológicas, foi exibida a singularidade nacional com que Netto esperava inserir o Brasil no mundo científico internacional. O que se pretendia expor e o que unia os conteúdos das diversas vitrinas era o papel original que cabia ao Museu Nacional do Rio de Janeiro cumprir na construção do ima- 
ginário do Império brasileiro e no panorama das ciências universais. A Exposição Antropológica Brasileira destacava as investigações da particularidade local, ainda não completamente estudada - as origens da "raça" brasileira. E isto era o máximo que as ciências podiam fazer pelo Império. Por este trabalho o imperador agraciou Netto com sua mais alta condecoração, a Ordem da Rosa. Em seu discurso de abertura da exposição, Ladislau assim sintetizara tais objetivos:

Este é o certame mais nacional que as ciências e as letras poderiam congratuladas imaginar e realizar no fito de soerguer o Império do Brasil no nível da intelectualidade universal (... . . E coube ao Museo Nacional [e a Ladislau Netto, inferimos nós] a imensa glória de havê-lo empreendido e de efetuá-lo ${ }^{16}$.

Entusiasmado com o sucesso alcançado, começou a planejar uma Exposição Antropológica Continental Americana para 1884, que seria uma "imensa, estupenda, grandiosa festa científica". Imaginava, seguindo o modelo internacional, a construção de um edifício monumental para abrigá-la, que depois pudesse servir para abrigar o próprio Museu Nacional, ou um novo Museu Arqueológico e Etnográfico, independente das demais coleções, que era um de seus sonhos e objetivos desde que assumira a direção do museu brasileiro. Ladislau Netto já havia ido à Amazônia e a diversas provínicias brasileiras coletar no campo, nas aldeias, nos cemitérios indígenas ou nos museus locais, objetos para sua exposição. Talvez tenha ido a Buenos Aires como parte de sua estratégia para a organização da "Exposição Antropológica Continental Americana", que serviria segundo ele para colocar o Brasil no que julgava ser seu merecido lugar nesse campo de estudos, à frente dos demais países da América do Sul.

Talvez o que viu por lá, nos museus de Burmeister, de Moreno, da Sociedad Científica, nas coleções de Florentino Ameghino, que também conheceu, e em mãos dos colecionadores particulares e comerciantes de antiguidades, tenha contribuído para diminuir suas expectativas. Se é certo que sua sonhada exposição não aconteceu, é certo também que seus intercâmbios com a Argentina se intensificaram. Em agosto de 1883, foi a vez de Ladislau Netto retribuir as honras que recebera em Buenos Aires. Organizou uma Fiesta Literária para Vicente Quesada, ministro plenipotenciário y Enviado Extraordinario de la República Argentina en el Império del Brasil, e seu filho Ernesto, diretor da Nueva Revista de Buenos Aires. Quesada, enviado ao Brasil para negociar a sempre polêmica questão da região de Missiones, propunha um estilo diferente de diplomacia 
que passava, entre outros aspectos, pela realização de reuniões sociais "con todo el esplendor que conviene aquí, donde debemos ser potencia influyente y no en Europa, donde no podemos influir" ${ }^{17}$. Em um período de cordiais relações diplomáticas entre os dois países, agora quem ganharia a Ordem da Rosa seria Burmeister.

A convite de Ladislau Netto e atendendo às suas solicitações de intercâmbio "por algum fósil de los más grandes del Rio de la Plata”, Burmeister foi autorizado pelo governo argentino, em 19 de junio de 1886, a permutar um "ejemplar fósil de Scelidotherium que existia por triplicado em Buenos Aires por 10 cueros de mamíferos; 70 cueros de pajaros e 80 especies de mariposas y otros insectos que faltavam en las colecciones do museo argentino"18. E em um testemunho eloqüente das boas relações que mantinham os dois museos, Burmeister foi pessoalmente ao Rio de Janeiro, aos 79 anos de idade, acompanhar a montagem do esqueleto fóssil que doara. Em um período em que todos os museus se esforçavam em exibir o maior número possível de esqueletos montados e peças reconstruídas, e em que o Museu de Buenos Aires, com seus esqueletos montados era famoso e invejado por todos os diretores de museus latino-americanos, este foi um presente valiosíssimo que, aliás, continua exposto até hoje.

A viagem de Burmeister foi coroada de êxito. O esqueleto bem armado foi admirado repetidas vezes pelo imperador brasileiro D. Pedro II, que visitou o museu acompanhado de toda a Família Imperial, inclusive de seus netos. Burmeister, como Ladislau Netto, foi também agraciado com as insígnias de dignitário da Ordem da Rosa, numa veneração do imperador às ciências e a seus representantes ${ }^{19}$. Ele manteve uma correspondencia cordial e amistosa com Burmeister ${ }^{20}$. Em cartas, Netto lhe informava sobre os naturalistas que davam grande honra ao museu: dois alemães, Fritz Müller e Hermann von Ihering, e o suíço Emilio Goeldi. Estes dois últimos, jovens então, seriam os futuros diretores do Museu Paulista organizado em 1894, e do Museu Paraense de História Natural e Etnografia, em Bélem do Pará, que por sua vez também manteriam intercâmbios com os museus argentinos.

Burmeister lhe contava da morte da cunhada; que seu filho Carlos fora à Patagônia fazer coleções para o museo de Buenos Aires; que embora recordasse "con mucho placer su estada en Rio" e pensasse em repeti-la, talvez não o fizesse porque teria que levar "su señora, y viajes con señoras no eran un recreo, y sino generalmente mas una incomodidad que preferia evitar...”. Insistia que Ladislau Netto lhe conseguisse junto à Biblioteca Nacional brasileira, em troca dos Anales, os volumes que fal- 
tavam em Buenos Aires da Flora Brasilienses, publicação considerada caríssima à época.

Buenos Aires, no imaginário de grande parte dos diretores de museus latino-americanos, ocupou a posição do principal museu latino-americano dedicado à paleontologia dos grandes mamíferos terciários encontrados em território argentino. Diferentemente, a marca que Ladislau Netto buscou consolidar no Rio de Janeiro, seguindo os própositos de seus antecessores, foi a de um museu metropolitano geral, com coleções de caráter universal que contemplassem particularmente coleções arqueológicas, etnográficas e antropológicas.

Burmeister, que integrava aquela velha geração de naturalistas que Darwin nunca esperou convencer, divulgou seus trabalhos e, de fato, ao mesmo tempo que emprestava seu prestígio à instituição, e o desta ao país, utilizava-se de suas coleções e do espaço profissional conquistado para desenvolver seus trabalhos. Constituiu assim um museu científico nas áreas de suas especialidades. Anti-darwinista convicto, cujas posições só se alterariam em 1889, aos 84 anos, um pouco antes de morrer, foi um autêntico "seeker" ${ }^{21}$ : um naturalista independente, não financiado por seu país de origem, que buscava através dos espaços institucionais que conseguia, meio próprios para dialogar com seus pares europeus e norteamericanos, realizar suas pesquisas e publicá-las. Profundamente absorvido em seus trabalhos no museu que conseguira organizar para poder desenvolvê-los, tinha no entanto consciência claríssima da imagem que os políticos e a elite de Buenos Aires criaram de seu gabinete de estudos. E conforme com essa consciência, atuava em favor de seus interesses pessoais, científicos, profissionais, políticos. Estes incluíam também a missão de alimentar a importância simbólica que esta elite, a que estava perfeitamente integrado, atribuía a seu museu e a suas publicações regularmente financiados.

Quanto a esses temas, seus argumentos de autoridade científica e política em prol da não-transferência do Museo Público de Buenos Aires, quando da federalização da capital, são por si só suficientemente eloqüentes. Considerando-se o principal interessado no "pretendido transporte del museo a la nueva ciudad, La Plata”, lembra, e este talvez seja um argumento decisivo, que "la majoria de los objectos del Museo del tiempo antes de mi dirección son regalos, hechos por familias habitantes de Buenos Ayres mismo (...) para dar a si mismo una satisfación patriotica, pero no para dejar los figurar en un otro lugar de la provincia”"(os grifos são meus). 
Outros argumentos decisivos, riscados nesses seus papéis de rascunho, são seu pedido de "jubilacion despues de 23 años" de dedicação ao Museo Público de Buenos Aires e ao país, e sua declaração de não poder prestar auxílio à transferência do museu, por não ser conivente con o "destino de la corrupcion de mi propria obra" ${ }^{22}$. Em $1^{0}$ de outubro de 1884, o Museu Público de Buenos Aires foi nacionalizado e, para La Plata, a nova capital da província, seria transferido o Museu Antropológico e Arqueológico, constituído pelas coleções que Francisco Moreno doara à provincia de Buenos Aires em 1877.

A essa altura, os museus de Buenos Aires e Rio de Janeiro já não eram mais desde alguns anos os únicos dedicados à História Natural na Argentina ou no Brasil. Novos episódios de cooperação e de disputas, em busca de perspectivas para os museus do próximo século começavam a se delinear. Para a geração seguinte de diretores de museus, na transição do século, estabelecer rupturas com o passado dessas mesmas instituições foi fundamental. Embora estes não pudessem deixar de reconhecer os méritos de seus antecessores, seriam implacáveis na crítica às suas crenças científicas, seus métodos de trabalho, autoritarismo, individualismo, estrangeirismo, no sentido de demarcar novos campos profissionais, novas práticas científicas, quando não mesmo criar suas próprias novas instituições.

\section{MISSÕES CIENTÍFICAS E CIVILIZADORAS}

Aos museus centenários e aos novos que se criariam nas décadas de 1880 e 1890 na Argentina e no Brasil, vincularam-se e destacaram-se como seus construtores: Francisco Pascásio Moreno (1852-1919), em La Plata; Carlos Berg (1843-1902) em Montevidéu e Buenos Aires; Florentino Ameghino (1853/54-1911) e Juan B. Ambrosetti (1865-1917) em Buenos Aires; Barboza Rodrigues (1842-1909) em Manaus; Emilio Goeldi (18591917) em Belém; João Batista de Lacerda (1846-1915) no Rio de Janeiro, e Hermann von Ihering (1850-1930) em São Paulo. Se não se tratava de novo de começar do zero, tratava-se sim de novamente adequar aspectos institucionais e concepções científicas ao tom da época.

Construir museus no final do século, tem sua explicação nas palavras de Miranda Ribeiro, zoólogo do Museu Nacional do Rio de Janeiro:

Estava morta a 'definição lineana de espécie', mas não o estava a luta pelo processo da evolução nem da origem, pois era compreensível que as idéias preconcebidas não fossem abandonadas de chofre, após tão longo período de domínio. Partidários e contrários exigiam provas - as séries demonstra- 
tivas dos elos da cadeia da evolução. Era natural que dessa procura constante das relações de parentesco de uma espécie para outra e das variações de cada espécie, os museus entrassem numa nova fase mais propriamente filosófica, ao passo que o acúmulo dessas provas ia gradativamente ligando entre si fatos até então incompreendidos ${ }^{23}$.

Particularmente nesse período, assinalado pela consolidação de mudanças profundas nos paradigmas das ciências naturais, rupturas foram essenciais para que os profissionais de museus demarcassem - em suas áreas de especialidade - seu novo campo de atuação científica, reclassificando coleções, estabelecendo sólidos intercâmbios científicos com museus e instituições científicas por todo o mundo, publicando seus trabalhos resultantes das análises das coleções de que dispunham e se empenharam em reunir. Se não romper fronteiras nacionais, pelo menos 'ampliá-las' foi uma prática familiar a esses diretores dos museus brasileiros e argentinos da transição do século. A demarcar limites territoriais em bases científicas em prol de seus países, dedicaram-se Francisco Moreno, o diretor do Museu de La Plata, na questão da "frontera argentinochilena”, ou Emilio Goeldi, na delimitação dos territórios entre Brasil e Guiana Francesa, o que lhe imortalizou o nome no Museu Paraense de História Natural e Etnografia, que dirigia na Amazônia.

"Apagar os títulos de desconhecido das cartas do Brasil e da natureza brasileira e mesmo sul-americana”, como dizia Miranda Ribeiro, era uma das funções principais que os diretores de museus atribuíam a si próprios e às suas instituições. Incorporar à Argentina ou ao Brasil os milhares de hectares de terras e de natureza "desconhecidas" significou em inúmeros casos recolher para depositar em La Plata, Buenos Aires, São Paulo, Belém ou Rio de Janeiro as flechas, armas e utensílios, quando não os próprios indígenas vencidos em batalhas, seja no "desierto" pampeano conquistado ou do oeste paulista até Rondônia.

E talvez resida aí um dos traços mais marcantes desse processo, em que construir ciência significou também inventar nações. Seja explicitamente, na participação, contribuição e aval científicos que os museus conferiram às anexações dos territórios indígenas e às políticas oficiais de extermínio, seja pela atribuição de valores de raros, "únicos" que os esqueletos, crânios e objetos comuns da vida cotidiana das nações indígenas ganharam ao serem transformados, como em um ritual, pelas mãos dos colecionistas, nos objetos científicos das mais preciosas coleções arqueológicas e etnográficas dos museus argentinos e brasileiros. Retirados de seus contextos, tais objetos perderam seu valor de uso e assumiram nos museus e 
coleções valores de mercadoria, como representantes do simbólico de outros lugares, outras sociedades, outros climas, outros tempos.

Os diretores de museus brasileiros e argentinos partilharam uma mesma fé inabalável nas ciências que eram a garantia do progresso, e se dedicaram à missão científica e civilizadora que lhes cabia: recolher nos museus (e onde não existissem era preciso criá-los) os testemunhos arqueológicos da cultura dos povos primitivos, e antes que desaparecessem coletar o maior número possível de esqueletos e crânios para os estudos comparativos que pudessem esclarecer as questões fundamentais da origem e do futuro da espécie humana, que do Amazonas ao Prata todos esperavam encontrar na América.

Neste clima, enfrentando o presente estão as teses de Ambrosetti, de que para que os indígenas não desaparecessem seria necessário que o progresso não alcançasse as regiões onde viviam, ou as polêmicas em que se envolveu von Ihering em torno do extermínio dos "índios bravos” de São Paulo. Voltadas para o passado, situam-se as teses de Ameghino, consoantes com sua época, sobre a origem "americana do sul” ou argentina da raça humana, que poderiam resolver de um só golpe os problemas da identidade argentina que ele mesmo bem encarnava em sua controversa origem de imigrante ou autóctone. Voltadas para o futuro, posicionamse também na mesma perspectiva as teses de João Batista de Lacerda, o diretor do Museu Nacional do Rio de Janeiro no início deste século. O médico fisiologista, antropologista de linha craniométrica, encontrara nos botocudos o exemplo máximo de inferioridade humana - o que, de alguma forma, não deixava de nos situar mais próximos de alguma pretendida origem - e na teoria evolucionista, a certeza do branqueamento inevitável da "raça brasileira" em um século, única esperança para o país de mulatos alcançar a civilização.

Fé como essas e empenhos em sua missões civilizadoras são as únicas coisas que podem explicar o que, aparentemente, impedia Moreno de entender quão concretamente seu amigo Sam Slick conhecia seu destino:

(... ) mi amigo Sam Slick, buen tehuelche, (... ) consintió en que hiciéramos su fotografia, pero de ninguna manera quiso que midiera su cuerpo y sobre todo su cabeza. No sé por qué rara preocupación hacía esto, (...) y un año después, cuando llegué a ese punto para emprender viaje a Nahuel Huapí, le propuse que me acompañara y rehusó diciendo que yo quería su cabeza. Su destino era ése. (...) Fue muerto alevosamente por otros dos indios (...) y en una noche de luna exhumé su cadáver, cuyo esqueleto se conserva en 
el Museo Antropológico de Buenos Aires; sacrilegio cometido en provecho del estudio osteológico de los Tehuelches ${ }^{24}$ (os grifos são meus).

Em busca de origens de povos, de animais e de territórios, os museus argentinos e brasileiros selariam muitas de suas cooperações e disputas. Onde e quando a antiguidade da vida humana não parecia suficiente para estabelecer continuidades históricas lineares até a construção das novas identidades nacionais, a discussão dos prós e contras sobre o entendimento dos processos evolutivos, apoiada nos eloqüentes testemunhos paleontológicos, trouxe sua contribuição. Ampliou dramaticamente a extensão do passado e permitiu a busca também das origens do próprio continente sem história.

En un pais cuya historia se extiende poco más allá de tres siglos: y en donde nuestros antepasados no nos han dexado monumentos ni vestigios algunos por onde congeturar algo que pueda llenar este gran vacio, parece que no nos queda otro medio que recurrir a la Geologia, esta nueva ciencia que se remonta más allá de todas las historias profanas, y con cuyas luces en muy pocos años se han hecho descubrimientos los más interessantes sobre los grandes acontecimientos de nuestro globo. No hay pues necesidad de recurrir a las fábulas para llenar los tiempos obscuros como lo han hecho los más célebres historiadores; podemos con más provecho y con más dignidad entretener a nuestros lectores preguntándolo a la Naturaleza ${ }^{25}$.

Esta era a justificativa com que o padre do Estado Oriental, Damásio Larranaga (1771-1848) - “o sábio brasileiro", segundo Cuvier, um dos primeiros naturalistas e colecionadores de fósseis, organizador das primeiras bibliotecas e museus nas regiões de Rio de la Plata e Banda Oriental - introduzia seus estudos sobre os depósitos de conchas fósseis nos arredores de Montevidéu, no início do século passado. Anos mais tarde, Burmeister, já aclimatado a essas praias, atualizando sua Historia de la Creacion, entraria na discussão acerca da "má denominação" do conceito de Novo Mundo. Do ponto de vista geológico, este não era mais jovem que o "antigo", bem como a espécie humana contemporânea aos grandes mamíferos extintos pelo dilúvio "existía simultaneamente, ántes de la época actual, en los dos continentes occidental y oriental”26.

Franscico Moreno também encontraria na geologia e geografia dos terrenos andinos os argumentos "naturais" que sustentariam as teses argentinas na questão de limites com o Chile. A traçar a origem do continente americano também se dedicaria Herman von Ihering, com o apoio fundamental de Florentino Ameghino, estabelecendo as conexões faunís- 
ticas que lhe permitiram teorizar acerca das antigas configurações geológicas dos continentes e de suas pontes.

Situar os estudos antropológicos, arqueológicos, etnológicos e paleontológicos nos museus - fortemente marcados pelas pesquisas zoológicas na transição do século na América Latina - implica necessariamente não perder de vista que então as áreas disciplinares não se delimitavam com a mesma rigidez atual, como por vezes a visão compartimentalizada das ciências de hoje não permite alcançar em toda a sua dimensão.

William Flower, o diretor do Museu Britânico já mencionado, em um discurso de 1889 , reproduzido como o primeiro artigo do tomo I da Revista del Museu de La Plata, entre outros temas discutia exatamente as questões essenciais das "ciências dos museus" modernas: a divisão das coleções do Museu Britânico naquelas de Antropologia, Arqueologia e de História Natural, nos anos de 1880; a separação da Paleontologia da Biologia e sua incorporação pela Geologia; o arranjo diferenciado das coleções de "investigaciones” para os especialistas e de "instruccion” para o público, e como não poderia deixar de ser, as "leyes que rijen la evolución de los seres organizados”.

Por esse mesmo discurso perpassavam algumas das preocupações que eram centrais também nos museus latino-americanos do final do século. Por isso a sua tradução e publicação. Ciências como a Paleontologia, Arqueologia, Etnografia, Antropologia ocuparam papéis de destaque nas discussões da época, apelando à memória, à origem, à civilização, à construção de nacionalidades imaginárias. Foi difícil ao espírito positivista do final do século XIX decidir qual ciência se encarregaria, por exemplo, dos estudos dos fósseis, ou de traçar a linha demarcatória entre ossos e fósseis de animais e humanos. E estes domínios, partilhados entre as ciências da terra e da vida, tornaram-se ainda mais complexos com a "intromissão" das ciências humanas. E foi exatamente nessas interfaces, terra, vida, seres humanos, que se especializaram também vários dos museus latino-americanos, nessa época. Enfatizando ora seus vínculos com as ciências geológicas, ora com as ciências biológicas, ora com os estudos arqueológicos e antropológicos, alguns dos diretores dos museus latinoamericanos da segunda metade do século XIX foram indubitavelmente os responsáveis pela institucionalização de disciplinas tais como a Arqueologia, Antropologia, Etnologia e Paleontologia na América Latina.

Dando sua contribuição à realização dos destinos de exceção a que Brasil e Argentina, entre outros países latino-americanos, se acreditavam providencialmente designados, no final do século XIX os museus brasi- 
leiros e argentinos também romperam fronteiras conceituais em suas vitrinas, publicações e intercâmbios. Na Argentina, a partir da confiança extremada nas possibilidades futuras do país e no seu destino civilizador diante dos demais países da América Latina, o fervor nacionalista encorajou então as visões explicitadas por José Ingenieros ou Ricardo Rojas, da importância do país como força hegemônica na América Latina. Suas vantagens de "território vasto, terra fecunda, clima temperado e raça branca” sobrepujavam as possíveis concorrências, dada a extensão territorial e superioridade populacional do Brasil, a que faltavam o clima e a raça, ou devidos aos ideais de dominação e expansionismo do Chile, a que faltavam "extensão e fecundidade”. No caso brasileiro, é amplamente conhecido nos discursos de construção da identidade nacional o desconforto causado pela convivência lado a lado de ideologias liberais em um regime escravocrata, idéias de homogeneização racial em um país de mulatos, ideais de uma nação educada, civilizada e moderna, onde o analfabetismo predominava.

Mas, pelo menos nas leituras que os diretores de museus fizeram de suas missões ao participarem dos debates candentes à sua época, também tratava-se de "tornar indiscutível a hegemonia do Brasil na América do Sul”: "Não devemos encarar essa tese política só pelo lado da força material bélica, do comércio e da indústria, mas sobretudo do ponto de vista da superioridade dos nossos recursos intelectuais e dos nossos institutos de ensino e de ciência”, diria João Batista de Lacerda, na direção do Museu Nacional do Rio de Janeiro, acrescentando que "não nos humilhamos copiando as boas criações de outros povos mais adiantados do que o nosso em artes e civilização. Assim tem feito a Argentina, e mui desvanecidos ficam os filhos desse país quando eles ouvem repetir por estrangeiros que Buenos Aires é uma miniatura de Paris”27.

Mas se havia que se garantir uma supremacia inclusive em nível de museus, não havia dúvidas, na transição do século, que o ideal a ser atingido estava nos museus ao sul do Rio da Prata. Do outro lado do Prata, de Montevideo à Amazônia, em Santiago ou em Valparaíso, os museus argentinos foram os mais invejados, porque modelares. Do lado de "lá" do Prata, Carlos Berg, assim como Ameghino, seu sucessor na direção do Museo argentino, enfrentando seus conflitos locais, passariam suas gestões destacando entre seus inúmeros problemas a necessidade de um novo edifício que rivalizasse com aquele suntuoso construído em La Plata.

Ao estudo, ao desenvolvimento e à vulgarização da História Natural e Etnologia do Estado do Pará e da Amazônia em particular, e do Brasil, da América do Sul e do continente americano em geral, se dedicava o 
Museu de Augusto Goeldi na Amazônia; a construir um Museu de Moluscos Sul-Americano se empenhou Hermann von Ihering em São Paulo, cujo regulamento da instituição não deixava qualquer margem de dúvida sobre seus objetivos: "o caráter do Museu Paulista em geral será o de um Museu Sul-Americano, destinado ao estudo do reino animal, de sua história Zoológica e da História Natural e cultural do homem”28.

A emancipar a Geologia da América do Sul das idéias preconcebidas de paleontólogos do hemisfério norte, que acreditavam poder julgar a antiguidade e a disposição geológica dos formações terciárias do hemisfério sul, sem suficiente conhecimento de causa, transferindo para o sul conceitos forjados em situações geológicas características do norte, dedicaram-se com afinco Hermann von Ihering e Florentino Ameghino, construindo um trabalho de cooperação científica ímpar no continente: "Entre nós, acredito que a nossa posição com os senhores americanos é cientificamente a mesma que infelizmente já é politicamente. Verdadeira ajuda imparcial e competente espero só se geólogos europeus de conformidade com o colega procederem a novos exames [sobre as coleções da Patagônia], escreveria Ihering à Ameghino a propósito de suas controvérsias com os norte-americanos das Princeton Expeditions ${ }^{29}$.

Em prol de "una reacción favorable hácia Sud-América, bajo el punto de vista intelectual" de parte de "los hombres de estudio del Norte", dedicou-se Moreno desde o editorial do primeiro tomo da Revista del Museo de La Plata, que esperava abrigar na cidade construída no deserto reuniões científicas internacionais que fariam juz às vastas coleções do "pasado y presente austral americano", que abrigava o museu do futuro argentino e latino-americano ${ }^{30}$.

O que se invejou e disputou foram primazias científicas, concepções de museus e projetos de investigações que iam muito além de limites nacionais. Fundamentalmente porque envolvidos nos dilemas que se referiam à definição dos papéis sociais que caberiam aos museus no século que se iniciava, os projetos desses museus longe de serem pensados apenas como locais, circunscritos a suas regiões específicas, incorporavam dimensões continentais. Musealizavam ambientes naturais de estudos que as fronteiras políticas entre os países não dividiam, partilhavam interesses científicos que se estendiam pelo menos por toda a América do Sul e buscavam, cada um a seu turno, liderar uma sonhada hegemonia do sul, frente ao norte. 


\section{NOTAS}

Agradecimentos: ao Museo Etnográfico/UBA-Argentina, à Fundação Rockefeller, ao CNPq e à FAPESP que têm apoiado minhas pesquisas sobre os museus latino-americanos, e sobre a emergência e consolidação das ciências naturais no Brasil.

${ }^{1}$ LOPES, M.M. “Cooperação Científica na América Latina no final do século XIX: os intercâmbios dos museus de ciências naturais”. In INTERCIENCIA. Caracas, ago, 2000, vol. 25, $\mathrm{n}^{\circ} 5$, pp.1-7.

${ }^{2}$ As referências aos museus brasileiros, quando não citadas estão em: LOPES, M.M. O Brasil descobre a pesquisa científica: os museus e as ciências naturais no século XIX. São Paulo: Hucitec, 1997.

${ }^{3}$ HALPERIN DONGHI, T. El espejo de la Historia. Problemas argentinos y perspectivas latinoamericanas. (2 $2^{\underline{a}}$ ed. Ampliada). Buenos Aires: Ed. Sudamericana, 1998.

${ }^{4}$ FONSECA, M. R. de G. F da "A única ciência é a pátria: o discurso científico na construção do Brasil e do México (1770-1815). Tese de doutoramento. Depto. de História. FFLCH - USP. 1997. Ver também: PRADO, M.L.C. A Formação das Nações Latino-Americanas: anticolonialismo, antiimperialismo, constituição das oligarquias. A América latina é livre? São Paulo: Atual, 1987.

${ }^{5}$ LOPES, M.M. “A formação de Museus Nacionais na América Latina Independente”. Anais Museu Histórico Nacional. Rio de Janeiro, 1998, v.30, pp. 121-145.

${ }^{6}$ Carta de Alberdi a Urquiza, Paris, 22 de setembro de 1856. HOUSSAY, B. A. "La Personalidad de Gérman Burmeister”. Crónica. Physis, 1942, tomo XIX, p. 283.

${ }^{7}$ PODGORNY, I. “Alfred Marbais du Graty en la Confederación Argentina”. El Museo Soy Yo. Ciencia Hoy, Buenos Aires, 1997, vol. 17, n 38, pp. 48-53. BOSCH, B. En la Confederacion Argentina 1854-1861. Buenos Aires: EUDEBA, 1998. Documentação relativa à organização de "un museo ó Exposicion Provincial Permanente" em função da participação na Exposição Universal de Paris de 1855. Facultad de Farmacia, UBA. Archivos Bonpland, Caja 1, doc. 298, 10/10/1854.

${ }^{8}$ Documento 309, de 22 de dezembro de 1870. Carpeta 1870. Archivo de la Secretaria. Años 1870 al 1880. Archivo Museu Argentino de Ciencias Naturales (MACN).

${ }^{9}$ HOLMBERG, E.L. El Museo de Buenos Aires. Su pasado, su presente, su porvenir. El Naturalista Argentino. Rev. de Hist. Nat. Tomo I, entrega 2aㅡ, Buenos Aires, febrero, $1^{\circ}$ de 1878 : 33-43, p.39.

${ }^{10}$ GUTIÉRREZ, J. M. Actas de la Sociedad Paleontológica. Sesion del 10 de julio de 1867, p.XXVII.

${ }^{11}$ FLOWER, W. “Los Museos de Historia Natural”. Revista del Museo de La Plata. Tomo I. 1890-91: 2-25.

${ }^{12}$ Documentos. ${ }^{\text {os }} 195$ e 206, Pasta 8, 1869. Arquivos do Museu Nacional do Rio de Janeiro e documento 263, de 20/4/1870. Carpeta Año 1870. Caja Años 1870-1880. Archivo de la Secretaria. MACN. Ver: LOPES, M.M. Nobles Rivales: estudios comparados entre el Museo Nacional de Río de Janeiro y el Museo Público de Buenos Aires. In: Montserrat, M. (comp.) La ciencia en la Argentina entre siglos. Textos, contextos e instituiciones. Buenos Aires: Manantial, 2000: 277-296. 
${ }^{13}$ ZEBALLOS, E. El Museo Nacional de Rio de Janeiro. Anales de la Sociedad Cientifica Argentina, tomo III, 1877: 269-275. Cf. p. 269.

${ }^{14}$ BERG, C. Conferencia pública en honor del socio corresponsal doctor don Ladislao Netto, el 12 de octubre de 1882. Anales de la Sociedad Científica Argentina. Tomo XIV, 1882: 146; NETTO, L. "Observaciones sobre la teoría de la evolución. Anales de la Sociedad Cientifica Argentina. Tomo XIV, 1882: 147-158. Ver: GUALTIERI, R.C.E. As ciências naturais e o darwinismo no Brasil: a influência do evolucionismo na produção científica do Museu Nacional do Rio de Janeiro (1876-1915). In: LOPES, M.M. e FIGUEIRÔA, S.F. de M. Gênero, Ciência e Tecnologia na história latino-americana. V Congresso Latino-Americano de História das Ciências e da Tecnologia. RESUMOS. Campinas: UNICAMP, 1998, pp. 118-120.

${ }^{15}$ MORENO, F. P. El origen del hombre sud-americano. Razas y civilizaciones de este continente. Anales de la Sociedad Científica Argentina. Tomo XIV, 1882: 182-223. Cf. p.191.

${ }^{16}$ NETTO, L. de S. M. Prefácio. Archivos do Museu Nacional, v. VI, 1885, p. III.

${ }^{17}$ QUESADA, E. “Fiesta Literaria”. Celebrada en Rio de Janeiro, el 30 de agosto de 1883. Nueva Revista de Buenos Aires. Año III. Tomo VIII. Buenos Aires. 1883: 481. RATO SAMBUCETTI, S. La visión de los diplomaticos argentinos sobre monarquia y la republica en Brasil. Seminário "Argentina-Brasil en la transición al siglo XX. De la consolidación de las nacionalidades a la construcción de proyectos civilizatorios. Buenos Aires, nov. 1998: 2 (Draft).

${ }^{18}$ Documentos nos 881 a 883; 885, 889 e 893, Carpeta 1886. Caja 1886-1888. Notas de Germán Burmeister. Archivo MACN.

${ }^{19}$ Documento 889, Buenos Aires, 14 de agosto de 1886: Documento 893, Buenos Aires, 28 de agosto de 1886. Carpeta 1886. Caja 1886-1888. Notas de Germán Burmeister. Archivo MACN.

${ }^{20}$ As informações que se seguem estão nos documentos; 866, 881, 882, 883, 885, 889, 893 de fevereiro a agosto de 1886. Carpeta Año 1886. Notas de Germán Burmeister. MACN.

${ }^{21}$ PYENSON, L. "Functionaries" and "Seekers" in Latin America: missionary diffusion of exact sciences, 1850-1930. Quipu, v. 2, no. 3, set-dec, 1985: 387-420.

${ }^{22}$ Verso do documento 743 - 3/7/1884 - Resumen de presupusto de 1884 hasta 1885. Carpeta Año 1884, Documentacion Antigua. Archivo MACN.

${ }^{23}$ RIBEIRO, A. de M. A Comissão Rondon e o Museu Nacional. (Conferências realizadas pelo Professor, no Museu Nacional do Rio de Janeiro, em 1916). $2^{\underline{a}}$ ed. Min. da Agricultura. CNPI. Publicação 49. Rio de Janeiro. 1945: 53.

${ }^{24}$ MORENO, F. P. (1879) Viaje a la Patagonia Austral. Buenos Aires: Ed. Elefante Blanco, 1997: 105-106; PODGORNY (op.cit.).

${ }^{25}$ LARRAÑAGA, D. A. Escritos de D. Dámaso Antonio Larrañaga. Instituto Histórico y Geográfico del Uruguay. Edición Nacional. Montevideo: Imprenta Nacional, tomos I a III, $1922-1923$.

${ }^{26}$ BURMEISTER, H. Historia de la Creación. Exposición Científica de las fases que ban presentado la tierra y sus habitantes en sus diferentes periodos de desarrollo. Madrid y Barcelona: Gaspar Editores, (9ae ed.) s/d. Tomo segundo, p.310. 
${ }^{27}$ LACERDA, J.B de Os museus de história natural e os jardins zoológicos de Paris e de Londres. 0 Kew Garden. Rio de Janeiro: Papelaria Macedo 1912: 74 e 21.

${ }^{28}$ Regulamento do Museu Paulista do Estado de São Paulo. São Paulo: Typ. do Diário Oficial. Artigo 2을 1894: 4.

${ }^{29}$ IHERING, H. von. "Les mollusques fossiles du tertiaire et du crétacé superieur de l'Argentine”. Anales del Museo Nacional de Buenos Aires, série III, tomo VII, 1907: IX-X.

${ }^{30}$ MORENO, F. P. Al Lector. Revista del Museo de La Plata. Tomo I, 1890-91: VI. 